Clinicians have recently questioned this theory because of the different age ranges of women with the two conditions.

In our study not only was smoking twice as frequent as the local and national age matched expected frequency ${ }^{5}$ but the number of cigarettes smoked was increased in patients. Heavy smoking increases the risk of women developing periductal mastitis, but other factors may also have a role. Women with periductal mastitis should be warned that continued smoking may lead to recurrent mammary sepsis.

The close correlation between smoking and the degree of periductal inflammation suggests that smoking is directly implicated in the pathogenesis of periductal mastitis. The finding that increasing age rather than smoking was related to duct dilatation seems to confirm clinicians' view that periductal mastitis and duct ectasia are two separate diseases. Clearly the nomenclature of these diseases needs clarification to emphasise their different aetiologies.

1 Thomas WG, Williamson RCN, Davies JD, Webb J. The clinical syndrome of mammary duct ectasia. $\mathrm{Br} \mathcal{F}$ Surg 1982;69:423-5.

2 Dixon JMJ, Anderson TJ, Lumsden AB, Elton R, Roberts HM, Forrest PM Mammary duct ectasia. Brf Surg 1985;70:601-3.

3 Bundred NJ, Dover MS, Coley S, Morrison JM. Breast abscesses and cigarette smoking. Br f Surg 1992;79:58-9.

4 Schaffer P, Furrer G, Mermillod B. An association of cigarette smoking with recurrent subareolar breast abscesses. Int $\mathcal{F}$ Epidemiol 1988;17:810-3.

5 South Birmingham Health Authority. Annual public health report 1990. Canterbury: Parker, 1990.

(Accepted 25 fune 1993)

\section{Colourings, flavourings, and sugars in children's medicines in India}

\author{
M L Kulkarni, C Sureshkumar, \\ V Venkataramana
}

Department of Paediatrics, J J M Medical College, Davangere- 577 004, Karnataka, India M L Kulkarni, professor C Sureshkumar, resident V Venkataramana, resident

Correspondence to: Professor Kulkarni.

$B M \mp$ 1993;307:773

Numbers of liquid paediatric medicines containing alcohol, flavouring, and various bases and colourings $(n=499)$

\begin{tabular}{lc}
\hline & $\begin{array}{c}\text { No of } \\
\text { medicines }\end{array}$ \\
\hline Alcohol $^{\star}$ & 53 \\
Flavouring & 11 \\
Base: & \\
Syrup & 211 \\
Sorbitol & 25 \\
Aqueous & 14 \\
Dry syrup & 30 \\
Other & 9 \\
Not mentioned & 210 \\
Colouring:t & \\
Sunset yellow FCF & 91 \\
Caramel & 83 \\
Amaranth & 72 \\
Tartrazine & 51 \\
Erythrosine & 43 \\
Ponceau 4R & 37 \\
Carmoisine & 22 \\
Brilliant blue FCF & 14 \\
Other & 9 \\
Not mentioned & 138 \\
\hline
\end{tabular}

*Range $2 \cdot 3 \%-20 \%$.

†More than one colouring was used in some products.
Most liquid medicines are for children and are usually coloured, flavoured, and sweetened with various additives. The complex role of these additives in producing unwanted effects is generally not well appreciated and often ignored. Despite awareness among the public and doctors and cooperation from pharmaceutical companies developed countries still face the health hazards due to these agents. ${ }^{2}$ The position might be worse in a developing country such as India, where lack of awareness and lax regulations give a free hand to pharmaceutical companies. We therefore examined paediatric liquid preparations for their content of alcohol, sugars, flavourings, and colourings.

\section{Methods and results}

We surveyed all paediatric liquid preparations stocked in nine pharmacies randomly selected from 86 in Davangere, a south Indian town. We scanned the label and the insert giving prescribing information. Ayurvedic (herbal) preparations, which are occasionally found in such pharmacies, were excluded.

We studied 499 products, of which 176 were tonics, 142 cough syrups, 64 antibiotics, 48 analgesics or antipyretics, 23 antiemetics or antidiarrhoeals, eight antiamoebics, and 38 miscellaneous products. Overall, 401 products were manufactured by 142 national pharmaceutical companies and 98 by 30 regional (three to five state) companies. The study thus largely reflects what is happening in India.

Twenty three cough syrups, 23 tonics, five antipyretics, and two miscellaneous preparations contained alcohol, ranging from $2 \cdot 8 \%$ to $20 \%, 2 \cdot 3 \%$ to $14.3 \%, 8.95 \%$ to $10 \%$, and $2 \cdot 3 \%$ to $4 \%$ respectively. The table shows the numbers of products containing additives. Sixty three products did not mention any additives or specified that the product was free of them.

Twenty companies were randomly selected from the 172 to assess how many of their paediatric oral drugs were liquids. Of the 148 preparations, 32 were tablets and 116 liquids.

\section{Comment}

Additives used in medicines are generally considered to be inert, and their adverse reactions are often erroneously attributed to the active ingredients. Studies have proved, however, that the reactions caused by additives may not be trivial ${ }^{2}$ - for example, $5-10 \%$ of allergic reactions in asthmatic patients occur with sulphites and $0-40 \%$ with tartrazine. ${ }^{3}$ Many countries have therefore made it compulsory to include full details of the additives on the label. ${ }^{2}$ Our study shows that numerous products did not contain enough information about the additives used or claimed that they were absent, thus making it difficult for susceptible people to avoid additives.

In the United States more than 700 medicines contain alcohol. ${ }^{4}$ Because of toxicity and drug interactions the American Academy of Pediatrics has recommended against the use of alcohol in children's medicines. Many pharmaceutical companies in developed countries have consequently taken steps to reduce or remove alcohol from their products. ${ }^{4}$ The high alcohol content in all categories of children's medicines marketed in India is worrying.

The evidence relating sucrose in medicines to dental caries led to the development of sugar free formulations in Western countries, ${ }^{3}$ and nearly a quarter of British pharmacists sell only sugar free medicines when available. ${ }^{5}$ In contrast, we found that $82 \%$ of preparations had a syrupy base and few listed the amount of sugar.

Reports of adverse effects resulted in less frequent use of colourings in medicines. In two studies, from Britain $^{2}$ and Switzerland, ${ }^{3}$ only a quarter of formulations contained colourings, whereas in our study $72 \%$ of products contained colourings. Most of the remaining products were also coloured but did not specify which colouring had been used.

We found that less than $3 \%$ of products mentioned the flavouring used. Several chemicals are needed to produce one flavour, so isolating the culprit is impracticable-for example, synthetic strawberry requires 30 ingredients. ${ }^{1}$

In our study nearly $80 \%$ of children's oral medicines were produced as liquids, although generally tablets may be used effectively in children. Such a variety of liquid preparations adds to the economic burden of the poor and is obviously unnecessary. Strict regulations and ethical and judicious use of liquid medicines by practitioners are necessary to contain the problem of additives in medicines.

1 Kumar A, Weatherly MR, Beaman DC. Sweeteners, flavouring and dyes in antibiotic preparations. Pediatrics 1991;87:352-60.

2 Pollock I, Young E, Stoneham M, Slater N, Wilkinson JD, Warner JO. Survey of colourings and preservatives in drugs. $B M \mathcal{F} 1989 ; 299: 649-51$.

3 Kolly M, Pecoud A, Frei PC. Additives contained in drug formulations most frequently prescribed in Switzerland. Ann Allergy 1989;62:21-5.

4 American Academy of Pediatrics-Committee on Drugs. Ethanol in liquid preparations intended for children. Pediatrics 1989;73:405-7.

5 Holmes A, Davidson LE. Sugar-free medicines: a lost opportunity. Br Dent $f$ 1987;163:240-1.

(Accepted 18 fune 1993) 